\title{
Labor After Cesarean
}

National Cancer Institute

\section{Source}

National Cancer Institute. Labor After Cesarean. NCI Thesaurus. Code C113423.

Labor in a woman who has had one or more previous cesarean births. 